\title{
Medical Image of the Week: Partial Anomalous Pulmonary Venous Return
}

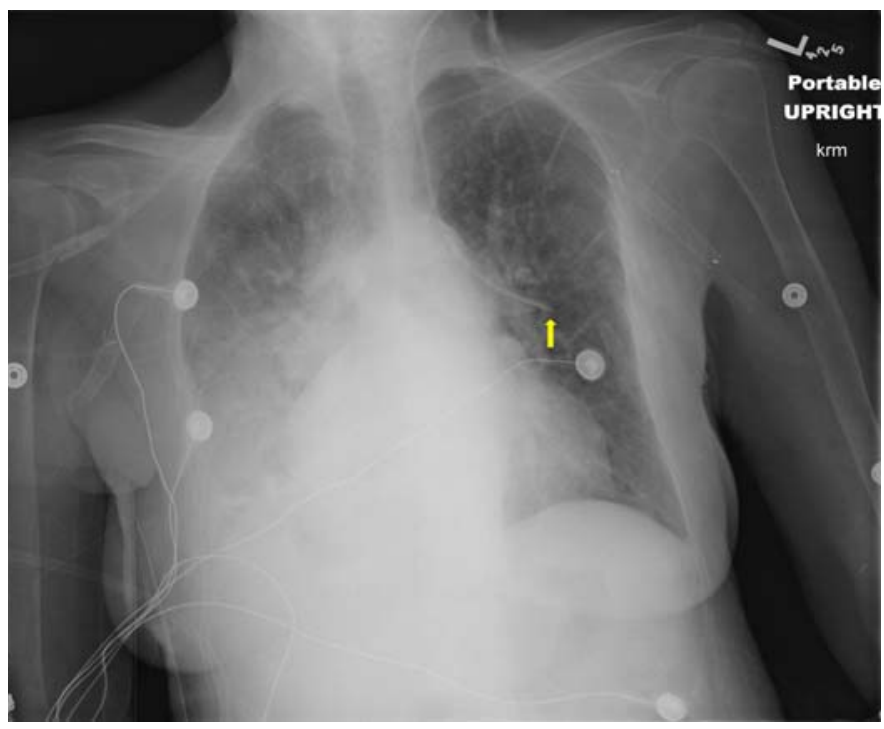

Figure 1. Chest radiograph status post left internal jugular central line placement with arrow pointing to tip of catheter.
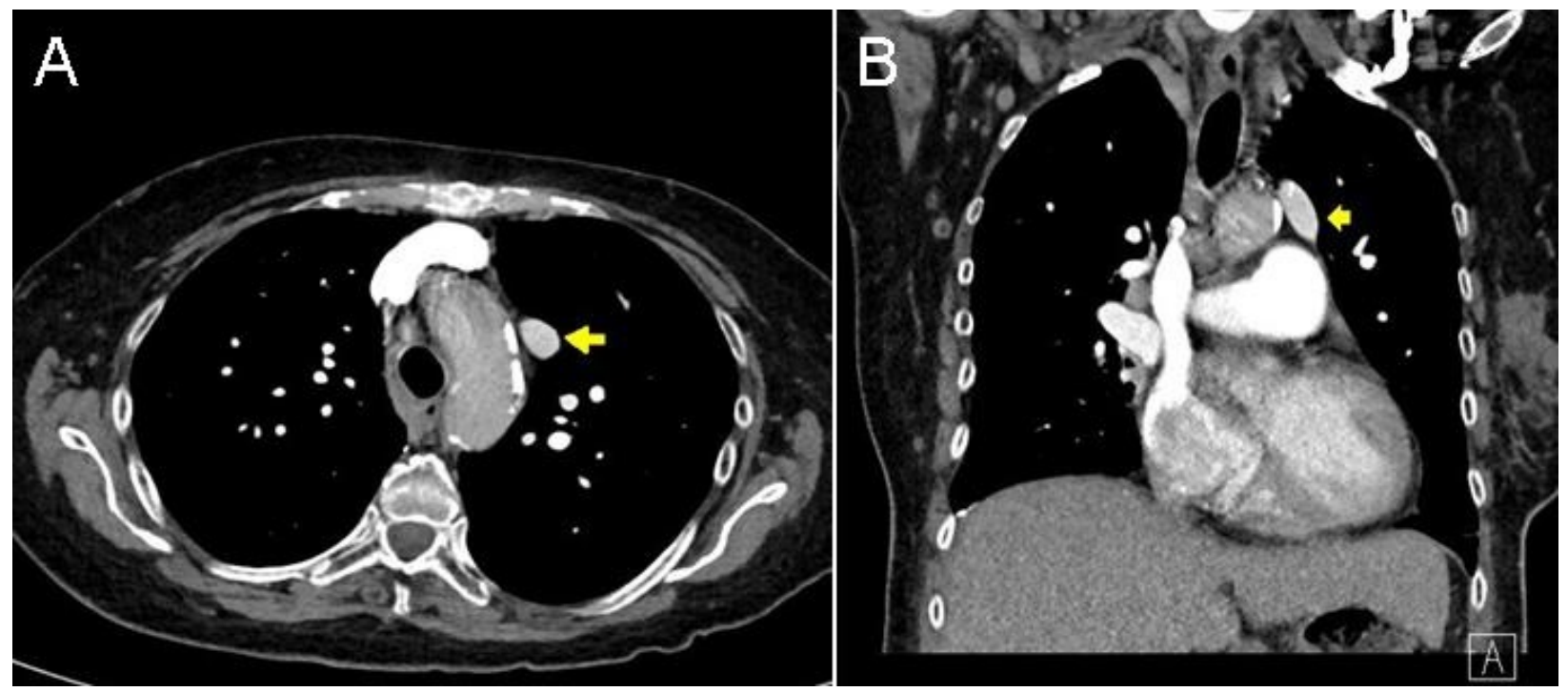

Figure 2. Axial (Panel A) and coronal (Panel B) views of contrast CT chest showing anomalous pulmonary venous return (yellow arrow).

A 69 year old woman presented with septic shock secondary to a urinary tract infection. A chest radiograph (Figure 1) done after uneventful placement of a left internal jugular central line showed aberrant position of the catheter.

Review of a past contrast-enhanced CT chest (Figure 2) revealed an anomalous pulmonary venous return with a pulmonary vein draining to the brachiocephalic vein. 
Partial anomalous pulmonary venous return (PAPVR) is a rare congenital defect which results in a left-to-right shunt. The prevalence was $0.1 \%$ in one retrospective study of 45,538 contrast-enhanced chest CT scans (1). Diagnosis can be made with echocardiography, angiography, right heart catheterization, or computed tomography. PAPVR is traditionally associated with atrial septal defects, and patients are often asymptomatic. Clinical manifestations occur when there is significant shunting and include syncope, right heart failure, and pulmonary hypertension (2).

Candy Wong MD; Tammer Elaini $\mathrm{MD}^{2}$; Naser Mahmoud $\mathrm{MD}^{1}$, and Josh Malo MD ${ }^{1}$ ${ }^{1}$ Division of Pulmonary, Allergy, Critical Care, and Sleep Medicine. Department of Medicine.

${ }^{2}$ Department of Medicine

University of Arizona

Tucson, AZ

\section{References}

1. Ho M, Bhalla S, Bierhals A, Gutierrez F. MDCT of partial anomalous pulmonary venous return (PAPVR) in adults. J Thorac Imaging. 2009;24(2):89-95. [CrossRef] [PubMed]

2. Kivisto $\mathrm{S}$, Hanninen $\mathrm{H}$, Holmstrom $\mathrm{M}$. Partial anomalous pulmonary venous return and atrial septal defect in adult patients detected with 128-slice multidetector computed tomography. J Cardiothorac Surg. 2011;6:126. [CrossRef] [PubMed] 